\begin{tabular}{|c|c|c|}
\hline \multirow{3}{*}{$\begin{array}{r}\text { Case Reports in } \\
\text { Gastroenterology }\end{array}$} & \multirow{2}{*}{\multicolumn{2}{|c|}{ Case Rep Gastroenterol 2016;10:743-748 }} \\
\hline & & \\
\hline & $\begin{array}{l}\text { DOI: } 10.1159 / 000450539 \\
\text { Publisnea onime: December 13, } 2016\end{array}$ & $\begin{array}{l}\text { (C) } 2016 \text { The Author(s) } \\
\text { Published by S. Karger AG, Basel } \\
\text { www.karger.com/crg }\end{array}$ \\
\hline & \multicolumn{2}{|c|}{$\begin{array}{l}\text { This article is licensed under the Creative Commons Attribution-NonCommercial } 4.0 \\
\text { International License (CC BY-NC) (http://www.karger.com/Services/OpenAccessLicense). } \\
\text { Usage and distribution for commercial purposes requires written permission. }\end{array}$} \\
\hline
\end{tabular}

\title{
A Rare Case of Intraductal Papillary Mucinous Neoplasm of the Biliary Duct in a Patient with Prostate Adenocarcinoma
}

\author{
Ravish Parekh Gregory Krol Cyrus Piraka Surinder Batra \\ Henry Ford Health System, Detroit, MI, USA
}

\section{Keywords}

Intraductal papillary mucinous neoplasm $\cdot$ Bile duct $\cdot$ Mucinous neoplasm

\begin{abstract}
Intraductal papillary mucinous neoplasms (IPMNs) are mucin-producing papillary neoplasms of the pancreatic or biliary ductal system that exhibit variable cellular atypia and cause ductal dilation. There are few reported cases of IPMN arising from the biliary tree in the literature. It has a higher propensity to undergo malignant transformation compared to IPMN arising from the pancreatic duct. An 80-year-old male underwent cross-sectional tomography (CT) imaging of the abdomen for evaluation of prostate adenocarcinoma, which revealed an incidental $2.3 \times 2.7 \mathrm{~cm}$ soft tissue mass centered at the porta hepatis with diffuse dilatation of the left intrahepatic biliary ductal system and mild prominence of the right intrahepatic ductal system. Endoscopic ultrasound showed 2 adjacent hilar masses involving the common hepatic duct and the left hepatic duct with protrusion of the tissue into the lumen of the duct and upstream ductal dilatation. Endoscopic retrograde cholangiopancreatography revealed a large filling defect in the common hepatic duct extending into the left hepatic duct. A large
\end{abstract}


amount of clot and soft tissue with a fish-egg appearance was retrieved. The patient underwent left hepatic lobectomy, radical resection of the common hepatic duct with Roux-en-Y hepaticojejunostomy to the right hepatic duct. Histopathological examination of the resected specimen revealed intraductal papillary mucinous neoplasm with diffuse high-grade dysplasia. Follow-up CT scan of the abdomen 2 months after the surgery was negative for any masses.

\section{Background}

Intraductal papillary mucinous neoplasms (IPMNs) are mucin-producing papillary neoplasms of the pancreatic or biliary ductal system that exhibit variable cellular atypia and cause ductal dilation. IPMN develops from epithelial cells and has malignant potential. It usually arises from the pancreatic duct [1]. IPMNs have been classified as main duct (MD) type or branch duct (BD) type based upon the anatomic involvement of the pancreatic duct. Patients with involvement of both the main and branch ducts are referred to as having mixed-type IPMN. The MD-IPMNs are histologically more aggressive than BD-IPMNs and more likely to harbor a malignancy [2]. The male-to-female ratio for MD-IPMN has varied in reports from 1.1 to $3: 1$, and for BD-IPMN it has varied from 0.7 to 1.8:1 [3]. The risk factors of IPMN include cigarette smoking [4], diabetes, family history of pancreatic adenocarcinoma [5], Peutz-Jeghers syndrome [6], familial adenomatous polyposis syndrome [7], or familial pancreatic carcinoma [8].

There are few reported cases of IPMN arising from the biliary tree in literature. It has a higher propensity to undergo malignant transformation compared to IPMN arising from the pancreatic duct $[9,10]$. Surgery is the treatment of choice due to the higher propensity of malignancy [11]. Our patient was found to have an incidental biliary tract IPMN with highgrade dysplasia during the staging of newly diagnosed prostate adenocarcinoma.

\section{Case Presentation}

An 80-year-old male was evaluated for an elevated prostate-specific antigen level, and a biopsy of the prostate gland revealed adenocarcinoma with a Gleason score 9. The patient accomplished cross-sectional tomography (CT) imaging of the abdomen, which revealed an incidental $2.3 \times 2.7 \mathrm{~cm}$ soft tissue mass centered at the porta hepatis with diffuse dilatation of the left intrahepatic biliary ductal system and mild prominence of the right intrahepatic ductal system (Fig. 1).

On physical examination, the head, eyes, ears, nose, and throat were normal. There was no jaundice. The abdomen was soft, nontender, and nondistended, no masses or free fluid were found, and bowel sounds were normal. Laboratory evaluation revealed normal liver enzymes, lipase, and amylase. Carbohydrate antigen (19-9) was 35.2 units/mL (normal value $<35$ units $/ \mathrm{mL}$ ). The patient accomplished endoscopic ultrasound and endoscopic retrograde cholangiopancreatography. Endoscopic ultrasound showed 2 adjacent hilar masses involving the common hepatic duct and left hepatic duct with protrusion of the tissue into the lumen of the duct and upstream ductal dilatation with parenchymal atrophy (Fig. 2). Endoscopic retrograde cholangiopancreatography revealed a large filling defect in the common hepatic duct extending into the left hepatic duct. A large amount of clot and soft tissue with a fish-egg appearance was retrieved (Fig. 3). Two pigtail biliary stents were placed 
into the left hepatic duct upstream from the soft tissue mass. The biopsy of the soft tissue mass revealed IPMN of the bile duct with diffuse high-grade dysplasia and intramucosal carcinoma.

The patient underwent left hepatic lobectomy, radical resection of the common hepatic duct with Roux-en-Y hepaticojejunostomy to the right hepatic duct. Histopathological examination of the resected specimen revealed IPMN with diffuse high-grade dysplasia (Fig. 4). The surgical margins and lymph nodes were negative for carcinoma.

The postoperative course was complicated by intraabdominal abscesses and pneumonia, requiring intravenous antibiotics and CT-guided drainage. The patient was readmitted 2 weeks after discharge with worsening hypoxia and lung infiltrates. He was found to have eosinophilic pneumonitis secondary to the antibiotics daptomycin and meropenem that resolved with discontinuation of the medications.

A follow-up CT scan of the abdomen 2 months after the surgery was negative for any masses. The patient feels well and remains asymptomatic 12 months after the surgery.

\section{Discussion}

Intraductal papillary mucinous neoplasms (IPMNs) are intraductal, mucin-producing tumors arising from epithelial cells and have malignant potential. IPMN usually arises from the pancreatic duct. In the literature, there are few reported cases of IPMN arising from the biliary tree $[9,11-14]$.

IPMN of the bile duct is usually associated with higher levels of carbohydrate antigen 19-9 and carcinoembryonic antigen. It has a higher propensity to undergo malignant transformation compared to IPMN arising from the pancreatic duct $[10,11]$.

It produces large amounts of mucin, leading to mass effect and disturbances in the bile flow. It is associated with bile duct dilatation and rarely exhibits invasion of surrounding margins. The most common form of presentation is a benign neoplasm. In rare cases, bile duct dilatation is the only finding. It can lead to cyst formation or papillary proliferation and may have varying degrees of cellular atypia. The malignant potential rises with increasing size $(>3 \mathrm{~cm})[14,15]$. Multiple genetic mutations have been described [16].

Most IPMNs of the biliary tree are benign and noninvasive; however, due to increasing size and malignant potential, surgical resection is the treatment of choice. The surgical treatment is based on the location of the IPMN. Various surgical treatments include resection of a liver lobe, hepaticojejunostomy, pancreaticoduodenectomy, and bile duct resection [10, 15]. The patients with benign neoplasms have a good long-term prognosis and survival.

There is no known association between prostate cancer and biliary duct IPMN in the literature. The diagnosis of IPMN in our patient was incidental and did not seem to be related to the patient's underlying prostate adenocarcinoma.

\section{Conclusion}

Biliary tract IPMNs are rare but can potentially lead to malignant tumors. Surgery is the treatment of choice. Our patient's IPMN was $2.7 \mathrm{~cm}$ with high-grade dysplasia, which was successfully treated with surgical resection. 


\section{Case Reports in \\ Gastroenterology}

Parekh et al.: A Rare Case of Intraductal Papillary Mucinous Neoplasm of the Biliary Duct in a Patient with Prostate Adenocarcinoma

\section{Statement of Ethics}

The authors have no ethical conflicts to disclose.

\section{Disclosure Statement}

The authors have no conflicts of interest to disclose.

\section{References}

1 Adsay V, Mino-Kenudson M, Furukawa T, Basturk O, Zamboni G, Marchegiani G, et al: Pathologic evaluation and reporting of intraductal papillary mucinous neoplasms of the pancreas and other tumoral intraepithelial neoplasms of pancreatobiliary tract: recommendations of Verona consensus meeting. Ann Surg 2016;263:162-177.

-2 Serikawa M, Sasaki T, Fujimoto Y, Kuwahara K, Chayama K: Management of intraductal papillarymucinous neoplasm of the pancreas: treatment strategy based on morphologic classification. J Clin Gastroenterol 2006;40:856-862.

3 Ingkakul T, Warshaw AL, Fernandez-Del Castillo C: Epidemiology of intraductal papillary mucinous neoplasms of the pancreas: sex differences between 3 geographic regions. Pancreas 2011;40:779-780.

-4 Fukushima N, Mukai K: Pancreatic neoplasms with abundant mucus production: emphasis on intraductal papillary-mucinous tumors and mucinous cystic tumors. Adv Anat Pathol 1999;6:65-77.

5 Capurso G, Boccia S, Salvia R, Del Chiaro M, Frulloni L, Arcidiacono PG, et al: Risk factors for intraductal papillary mucinous neoplasm (IPMN) of the pancreas: a multicentre case-control study. Am J Gastroenterol 2013;108:1003-1009.

-6 Sato N, Rosty C, Jansen M, Fukushima N, Ueki T, Yeo CJ, et al: STK11/LKB1 Peutz-Jeghers gene inactivation in intraductal papillary-mucinous neoplasms of the pancreas. Am J Pathol 2001;159:20172022.

7 Maire F, Hammel P, Terris B, Olschwang S, O’Toole D, Sauvanet A, et al: Intraductal papillary and mucinous pancreatic tumour: a new extracolonic tumour in familial adenomatous polyposis. Gut 2002;51:446-449.

8 Poley JW, Kluijt I, Gouma DJ, Harinck F, Wagner A, Aalfs C, et al: The yield of first-time endoscopic ultrasonography in screening individuals at a high risk of developing pancreatic cancer. Am J Gastroenterol 2009;104:2175-2181.

-9 Subhash R, Valiyaveettil IA, Natesh B, Raji L: Biliary tract intraductal papillary mucinous neoplasm: a brief report and review of literature. Indian J Pathol Microbiol 2014;57:588-590.

10 Minagawa N, Sato N, Mori Y, Tamura T, Higure A, Yamaguchi K: A comparison between intraductal papillary neoplasms of the biliary tract (BT-IPMNs) and intraductal papillary mucinous neoplasms of the pancreas (P-IPMNs) reveals distinct clinical manifestations and outcomes. Eur J Surg Oncol 2013;39:554-558.

11 Barton JG, Barrett DA, Maricevich MA, Schnelldorfer T, Wood CM, Smyrk TC, et al: Intraductal papillary mucinous neoplasm of the biliary tract: a real disease? HPB (Oxford) 2009;11:684-691.

-12 Mo A, Brat G, Spolverato G, Pawlik TM: Intraductal papillary mucinous neoplasm of the liver: GI image. J Gastrointest Surg 2015;19:792-794.

13 Wang X, Cai YQ, Chen YH, Liu XB: Biliary tract intraductal papillary mucinous neoplasm: report of 19 cases. World J Gastroenterol 2015;21:4261-4267.

14 Rocha FG, Lee H, Katabi N, DeMatteo RP, Fong Y, D’Angelica MI, et al: Intraductal papillary neoplasm of the bile duct: a biliary equivalent to intraductal papillary mucinous neoplasm of the pancreas? Hepatology 2012;56:1352-1360.

15 Jung G, Park KM, Lee SS, Yu E, Hong SM, Kim J: Long-term clinical outcome of the surgically resected intraductal papillary neoplasm of the bile duct. J Hepatol 2012;57:787-793.

16 Sclabas GM, Barton JG, Smyrk TC, Barrett DA, Khan S, Kendrick ML, et al: Frequency of subtypes of biliary intraductal papillary mucinous neoplasm and their MUC1, MUC2, and DPC4 expression patterns differ from pancreatic intraductal papillary mucinous neoplasm. J Am Coll Surg 2012;214:27-32. 


\section{Case Reports in Gastroenterology}

\begin{tabular}{l|l}
\hline Case Rep Gastroenterol 2016;10:743-748 \\
\hline DOI: 10.1159/000450539 & $\begin{array}{l}\text { @ 2016 The Author(s). Published by S. Karger AG, Basel } \\
\text { www.karger.com/crg }\end{array}$ \\
\hline
\end{tabular}

Parekh et al: A Rare Case of Intraductal Papillary Mucinous Neoplasm of the Biliary Duct in a Patient with Prostate Adenocarcinoma

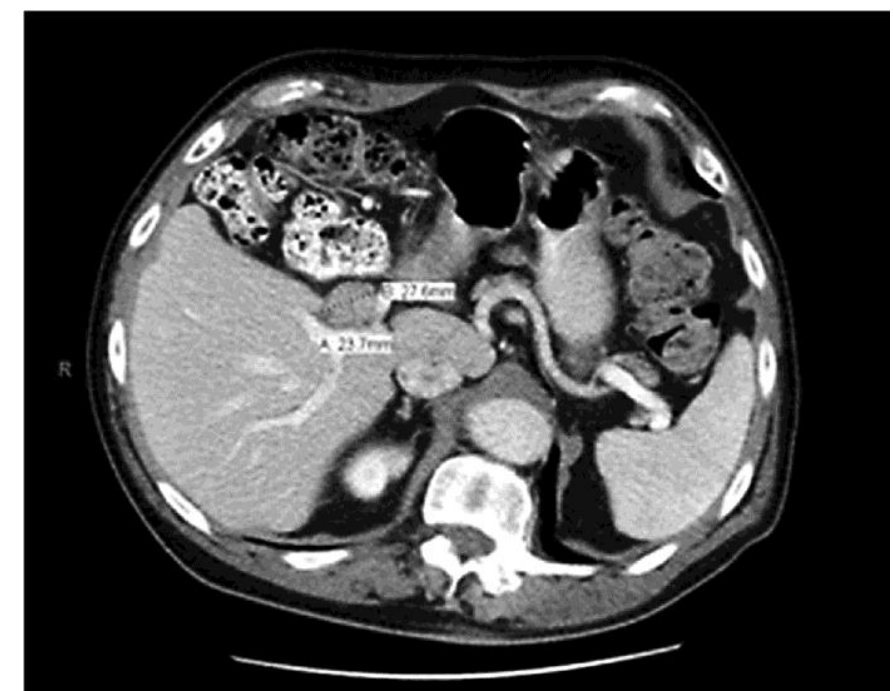

Fig. 1. Cross-sectional imaging showing the $23.7 \times 27.6 \mathrm{~mm}$ mass at the porta hepatis.

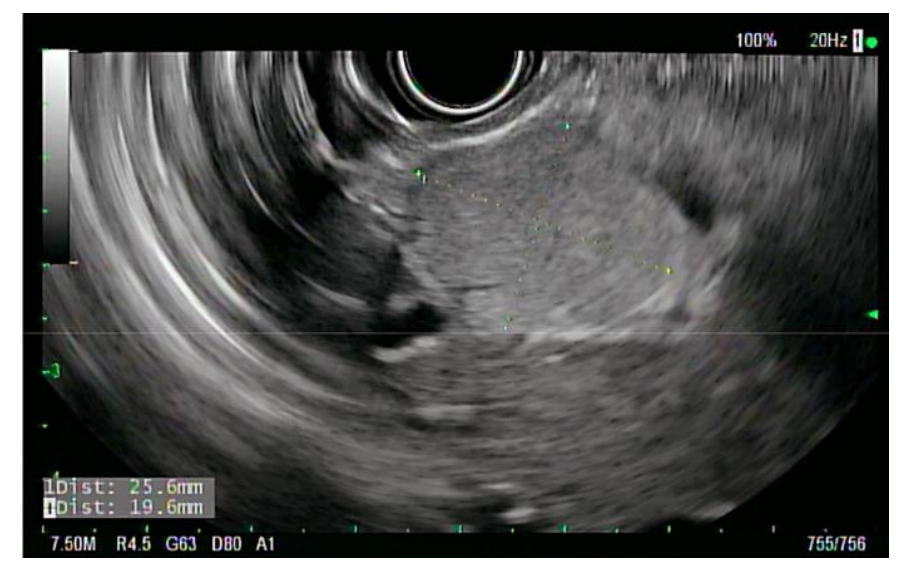

Fig. 2. Endoscopic ultrasound showing the hilar mass with protrusion into the Iumen of the duct. 


\section{Case Reports in Gastroenterology}

\begin{tabular}{l|l}
\hline Case Rep Gastroenterol 2016;10:743-748 \\
\hline DOI: 10.1159/000450539 & $\begin{array}{l}\text { C 2016 The Author(s). Published by S. Karger AG, Basel } \\
\text { www.karger.com/crg }\end{array}$ \\
\hline
\end{tabular}

Parekh et al.: A Rare Case of Intraductal Papillary Mucinous Neoplasm of the Biliary Duct in a Patient with Prostate Adenocarcinoma

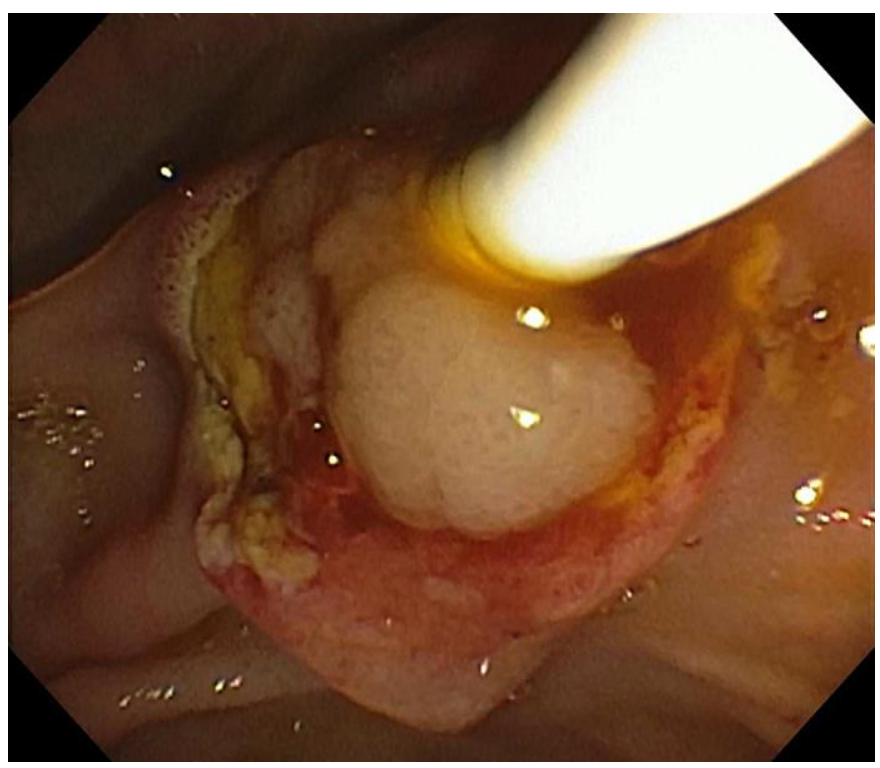

Fig. 3. Endoscopic retrograde cholangiopancreatography with removal of the soft tissue mass.

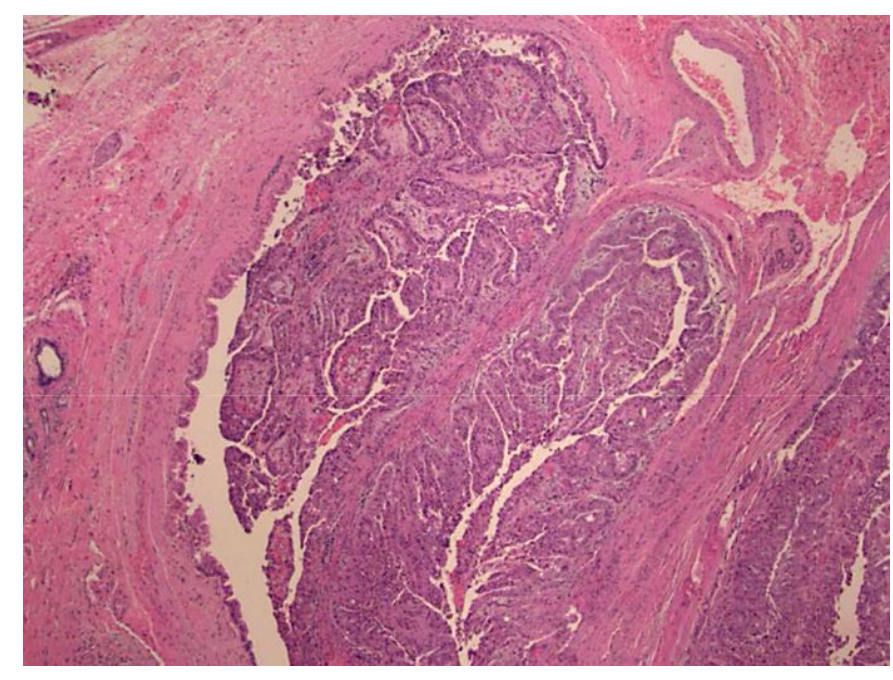

Fig. 4. Intraductal papillary neoplasm of the bile duct. Hematoxylin and eosin stain. Magnification $\times 200$. 